ISSN: 2644-1217

\title{
Basic Health Series: Cancer
}

\author{
Uqbah Iqbal* and Simon Smail \\ School of History, Suite P4, Level 31, AIA Cap Square Tower, Jalan Munshi Abdullah, 50100 Golden Triangle, Kuala Lumpur, Malaysia

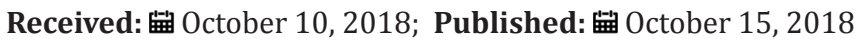 \\ *Corresponding author: Uqbah Iqbal, Life Planner, School of History, Suite P4, Level 31, AIA Cap Square Tower, Jalan Munshi \\ Abdullah, 50100 Golden Triangle, Kuala Lumpur, Malaysia
}

\section{Opinion}

This book explains cancer. The name of cancer is not only used to describe one disease, but also for all types of diseases comprising at least 200 different diseases. Many types of cancer can be cured quite easily if the initial treatment is given. More than half of existing cancer can be treated now though others are difficult to treat when in severe stages. All cancers have some of the same features. First, some cells in one part of the body begin to grow in irregular ways. The cells divide and multiply very fast. This results in the accumulation of abnormal cells called tumors. Second, abnormal cells can spread to other nearby tissues. Sometimes the cells can also spread to other parts of the body far from the original cancer cells. Third, the cells themselves have an abnormal structure. Some tumors are called benign and not cancerous. Normal mumps are benign tumors. Something that tumors will become cancerous only when the cells function abnormally. Most tumors may be triggered by a chemical or a virus called a carcinogen. This carcinogen interferes with DNA-controlled substances.

When cancerous cells produce tumors, they will continue to divide very quickly. The tumor will grow bigger. Cancer cells will also spread to other parts via tissue or grow in other parts of the body, across the natural division of one type of tissue to another. For example, cancer that starts in the lungs can spread into the muscles or bones in the chest wall. This means that if a tumor is untreated, it will become large and weighs up to several kilograms. Cancer cells sometimes spread into the bloodstream. Once in the bloodstream, the cancer cells will break down and move in blood circulation to other parts of the body. New cancer tumors will begin to grow in other places. This is called metastasis. The same situation can also occur if cancer cells are present in the lymph vessels. Lymphatic salts are a type of drainage system for the body. Cancer will attack one in three people in a population, although some types of cancer are more serious than others. Cancer can attack individuals at any age level, although in infants and children it is rare. Cancer is more common in middle-aged adults. Parents have the highest risk of developing cancer. The outcome of a cancerous half consists of individuals over fifty.

There are many types of cancer. In addition, there are also many factors that cause cancer. Sometimes certain types of cancer are inherited in a family. Some individuals may be born with higher risk of developing cancer when adults grow up. Nevertheless, most cancers are now caused by many different carcinogens and any one of these carcinogens may cause cancer. For example, tar in cigarette smoke is now known to cause at least nine out of ten lung cancers. But carcinogenes rarely cause cancer only once exposure to chemicals. Cancer is more likely to be due to repeated exposure and for long periods of exposure to chemicals. The duration of exposure to carcinogens and cancer can take a very long time, maybe ten years or more. Carcinogens are not only found in cigarette smoke, but it also exists in the chemicals used and possibly in certain foods. Irradiation in the form of X-rays or from radioactive substances may also act as a carcinogen. Some types of cancers may occur on the skin, though it is also a common place for benign proteins such as moles and small growths called papilomas. 
(C) This work is licensed under Creative Commons Attribution 4.0 License

Submit Article

DOI: 10.32474/OAJCAM.2018.01.000104



